\section{Hydromorphone patient-controlled
analgesia (PCA) after
coronary artery bypass patient-controlled
analgesia (PCA) after
coronary artery bypass patient-controlled
analgesia (PCA) after
coronary artery bypass surgery}

Norman R. Searle MD, * Micheline Roy RRT,* Georges Bergeron RRT, ${ }^{*}$ Jean Perrault PhD, $\dagger$ Jeanne Roof RN, $\ddagger$ Corrie Heermans RN, $\ddagger$ Micheline Courtemanche RN, $\ddagger$ Christine Demers RN, $\ddagger$ Raymond Cartier MD§
We conducted a study to compare the effectiveness of patientcontrolled analgesia (PCA) technique to conventional analgesic therapy (CAT) after coronary artery bypass grafi (CABG). The $P C A$ group received hydromorphone $0.1 \mathrm{mg} \cdot \mathrm{hr}^{-1}$ basal infusion and bolus doses of $0.2 \mathrm{mg} Q 5 \mathrm{~min}$ (maximum 1.2 $\mathrm{mg} \cdot \mathrm{hr}^{-1}$ ) while the CAT group received morphine $2.5 \mathrm{mg} i \mathrm{v}$ $Q 30 \mathrm{~min}$ prn until extubation followed by prn meperidine $1 \mathrm{mg} \cdot \mathrm{kg}^{-1}$ im $\mathrm{Q} 4 \mathrm{hr}$ or acetaminophen $325 \mathrm{mg}$ with codeine $30 \mathrm{mg}$ po (I or 2 tablets) when oral intake was possible. The degree of pain was assessed using a Visual Analogue Scale (VAS) starting after extubation and every 6-8 hr for the next $60 \mathrm{hr}$. Holter monitoring was initiated one hour after patient arrival in the Intensive Care Unit (ICU) and continued for 72 $h r$. Other measured variables were pulmonary function, sedation, side effects and total opioid requirements. Results show that the day-to-day VAS pain score decreased in the PCA group $(P<0.001)$ while it remained unchanged in $C A T$ patients. The PCA patients had lower VAS pain scores at extubation $(P<0.05)$. During the third postoperative day, the PCA group had a lower VAS pain score, a lower incidence of severe pain defined as a score $>5$ on the VAS scale, and a reduced incidence of myocardial ischaemia $(P<0.01)$. However, there was no difference in the duration, severity, area under the curve (AUC), or heart rate during ischaemic events. Postoperative pulmonary

\section{Key words}

ANALGESIA: Patient-controlled analgesia;

ANALGESIC: hydromorphone;

ANAESTHESIA: cardiac, myocardial ischaemia.

From the *Departments of Anaesthesia, $\ddagger$ Nursing, §Surgery and the $\nmid$ Research Center, Montreal Heart Institute, Montreal, Quebec, Canada.

This study was partly supported by a research grant from Knoll Pharmaceutical.

Address correspondence to: Dr. Norman R. Searle, Montreal Heart Institute, 5000 Belanger Street East, Montreal, Quebec, Canada HIT $1 \mathrm{C8}$.

Accepted for publication 23nd November, 1993. function was abnormal in both groups (NS) with minimal recovery by the fourth day. Opioid requirements, incidence of side effects and the degree of sedation were similar. We conclude that the PCA technique for analgesia provided slightly better results. The finding of a reduced incidence of myocardial ischaemia in the PCA group warrants further clinical investigation.

Nous avons effectué une étude comparative sur l'efficacité de l'analgésie contrôlée par le patient (PCA) par rapport au traitement analgésique conventionnel (CAT) chez des patients subissant une chirurgie de revascularisation myocardique. Après randomisation, le groupe PCA $(n=30)$ recevait une perfusion continue dhydromorphone $\left(0.1 \mathrm{mg} \cdot \mathrm{hr}^{-1}\right)$ avec des bolus de $0.2 \mathrm{mg} Q 5 \mathrm{~min}$ (maximum $1.2 \mathrm{mg} \cdot \mathrm{hr}^{-1}$ ), alors que le groupe $C A T(n=30)$ recevait morphine $2.5 \mathrm{mg}$ iv $Q 30 \mathrm{~min}$ prn jusqu'à l'extubation, suivie par mépéridine $1 \mathrm{mg} \cdot \mathrm{kg}^{-1}$ im $Q$ $4 \mathrm{hr}$ prn ou acétaminophène $325 \mathrm{mg}$ avec codéine $30 \mathrm{mg}$ po (1-2 comprimés) lorsque le patient pouvait s'alimenter. La perception de douleur fut évaluée à l'aide d'une échelle visuelle analogique (VAS) lorsque le patient fut extubé et à toutes les 6-8 hr pendant $60 \mathrm{hr}$. Un monitorage Holter de $72 \mathrm{hr}$ fut débuté I hr après l'arrivée du patient aux soins intensifs. Létude a aussi évalué les changements dans la fonction pulmonaire, la sédation, les effets secondaires et la quantité d'opiacés requise. Nos résultats démontrent que le degré de sévérité de la douleur a diminué significativement d'une journée à l'autre dans le groupe PCA $(P>0.001)$ comparativement au groupe $C A T$. $A$ l'extubation, les patients $P C A$ avaient moins de douleur ( $P$ $<0.05)$. Au troisième jour postopératoire, le groupe $P C A$ avait moins de douleur $(P<0.05)$, aucune incidence de douleur sévère $(P<0.01)$ et une incidence diminuée d'schémie myocardique $(P<0.01)$. Toutefois, il n'y avait pas de différence dans la durée, lintensité, la surface sous la courbe (AUC) et la fréquence cardiaque pendant les épisodes d'schémie myocardique. La fonction pulmonaire postopératoire était anormale dans les deux groupes $(P=N S)$ avec très peu de récupération après quatre jours. Les besoins en opiacés, lincidence des effets secondaires et le degré de sédation étaient similaires. Nous concluons que la technique de PCA procure une analgésie légèrement supérieure. Le fait qu'il y avait une diminution 
dans lincidence d'ischémie myocardique dans le groupe PCA nécessite d'autres investigations cliniques:

There are reports indicating that between $33-75 \%$ of patients complain of moderate to severe postoperative pain despite treatment. ${ }^{1,2}$ This inadequacy of pain relief is not related to the lack of effective analgesic agents but rather to the inappropriate manner in which these agents are administered. ${ }^{3,4}$ It has been suggested that health care professionals underprescribe analgesics for fear of causing respiratory depression and/or addiction. This is not to discredit the health care professionals, but it demonstrates that, despite motivation to relieve pain, deficiencies in knowledge and skills still preclude effective pain relief. 2,5 However, the inadequacy of acute pain relief cannot all be entirely attributed to the health care professionals. There appears to be a discrepancy between the description of pain by patients and their degree of satisfaction with analgesic therapy. ${ }^{6}$ Nevertheless, the recognition of the widespread inadequacies in postoperative pain management has prompted recent corrective endeavours.

Pain is a complex phenomenon which can trigger many reactions on the autonomous nervous system, resulting in adverse physiological consequences. It can alter the homeostatic regulation of humoral and neuroendocrine systems. Nontreated or ineffectively treated pain following major surgery affects the pulmonary function causing a reduction in lung volumes with atelectasis and mismatch in ventilation-perfusion. ${ }^{7,8}$ There is an increase in catecholamine release 9 with a potential risk for myocardial ischaemia and an increased incidence of thromboembolic complications. ${ }^{10}$

Numerous techniques are utilized for pain control following surgery. Patient-controlled analgesia (PCA) is one which allows patients to titrate small doses of analgesic medication within certain predetermined limits to control postoperative pain. This technique recognizes interpatient variability in analgesic requirements, and minimizes the delay between the perception of pain and its relief. Other characteristics of PCA include the reduction of anxiety by providing immediate access to pain-relieving medication as well as giving patients a certain measure of control over their medical needs. The efficacy of the technique has been well established for a variety of postoperative pain and other medical conditions. ${ }^{11-15}$ However, little information on the use of PCA after coronary artery bypass surgery (CABG) is available. ${ }^{16}$

The aim of this study was to compare the effectiveness and the suitability of PCA with a conventional analgesic therapy in patients undergoing CABG. The clinical variables of the study were chosen to compare pain score; the incidence, duration and severity of myocardial ischae- mia; pulmonary function as well as the degree of sedation and the incidence of side effects.

\section{Methods}

After institutional approval and informed written consent, 72 elective cardiac patients scheduled for CABG surgery were randomly assigned into two groups to receive either hydromorphone by PCA technique or the conventional analgesic therapy (CAT) regimen for control of their postoperative pain. Excluded from the study were patients ASA IV or V, older than 70 yr or undergoing emergency surgery. Patients with abnormal hepatic or renal function, previous sternotomy, unstable angina, preoperative insertion of an intraaortic balloon pump (IABP), or abnormal left ventricular ejection fraction $(<45 \%)$ were also excluded. Patients requiring reexploration for any reasons (haemostasis, tamponade, etc), unstable haemodynamic function with a cardiac index $<2 \mathrm{~L} \cdot \mathrm{min}^{-1} \cdot \mathrm{m}^{-2}$ necessitating pharmacological support and/or IABP to wean from bypass were excluded. In addition, patients with agitation or delirium on emergence, neurological complications and those unable to operate the PCA pump properly were excluded. The anaesthesia technique for cardiac surgery was selected by the attending staff anaesthetist and no standardized anaesthetic technique was imposed.

\section{Analgesia}

From the end of surgery until tracheal extubation, patients in the conventional analgesic therapy (CAT) group received morphine $2.5 \mathrm{mg}$ iv Q $1 \mathrm{hr}$ prn as judged necessary by the attending staff nurse. When patients recovered from anaesthesia, small increments of morphine $2.5 \mathrm{mg}$ were administered $\mathrm{Q} 30 \mathrm{~min}$ as required by the staff nurse for controlling pain until tracheal extubation the next morning. After tracheal extubation, patients received meperidine $1 \mathrm{mg} \cdot \mathrm{kg}^{-1} \mathrm{Q} 4 \mathrm{hr} \mathrm{prn}$, and when they could tolerate oral intake, they received oral medication consisting of acetaminophen $325 \mathrm{mg}$ with codeine $30 \mathrm{mg} \mathrm{1-2}$ tablets Q $4 \mathrm{hr}$ prn. Supplemental doses of meperidine $1 \mathrm{mg} \cdot \mathrm{kg}^{-1} \mathrm{im}$ were permitted if patients reported inadequate pain relief from oral medication. Records of the type and total analgesic requirements during the subsequent $72 \mathrm{hr}$ were kept for each patient.

Patients allocated to the PCA group received hydromorphone hydrochloride (Dilaudid, Knoll Pharmaceuticals, Canada) iv by a CADD-PCA pump (KabiPharmacia). They had been instructed on the use of the PCA pump during the preoperative visit and an instructional booklet providing more knowledge on the role and function of PCA was left at their bedside. Using a concentration of $0.5 \mathrm{mg} \cdot \mathrm{ml}^{-1}$, the pump was set to deliver a continuous infusion of hydromorphone $0.1 \mathrm{mg} \cdot \mathrm{hr}^{-1}$, 
and bolus doses of $0.2 \mathrm{mg}$ with a lockout period of five minutes and a maximum of six boluses per hour. For the PCA patients, the infusion was started one hour after arrival in the Intensive Care Unit (ICU). During the period following emergence from anaesthesia until tracheal extubation, nurses were instructed to administer intermittent boluses from the pump only if the patient could give an affirmative sign to the presence of pain. Following tracheal extubation, patients were allowed to receive hydromorphone with PCA pump for the next $60 \mathrm{hr}$ if they understood and were able to operate the pump. Records of total amounts of hydromorphone (mg) used as well as the total number of boluses sought and received were kept.

\section{Assessment of pain and sedation}

During the preoperative assessment, all patients were instructed on the use of the Visual Analogue Scale (VAS) to assess their perception of pain. Visual analogue pain scores were always measured at rest by the same two investigators (MR, $\mathrm{CH}$ ). Patients were requested to displace a cursor that was initially set in the middle. At the two extremities of the scale, the adjective descriptors of "no pain" (corresponding to 0 ) and "the worse pain ever felt" (corresponding to 10 ) were displayed. Before tracheal extubation, no VAS pain scores were measured but patients were questioned regularly by their nurse on the presence of pain. If the patient nodded affirmatively, an opioid bolus (morphine for the CAT group or hydromorphone for the PCA group) was administered. Visual analogue pain scores were measured at time of extubation and every 6-8 hr for the next $60 \mathrm{hr}$.

The sedation score was assessed by the same investigators using a four-point scale as follows: $0=$ awake, $1=$ easy awakening, 2 = awaken by physical stimulation, $3=$ difficult to awaken with physical stimulation. The sedation scores were assessed simultaneously with the pain score and at the same time intervals.

\section{Respiratory function}

On the day before surgery and daily for the next four days after tracheal extubation, the following lung variables were measured using a portable spirometer (Spiromate AS 600, Riko): vital capacity (VC), tidal volume (VT), breathing frequency (f), F/VT ratio, forced expiratory volume in one second $\left(\mathrm{FEV}_{1}\right)$ and the maximum negative inspiratory force (NIF). These respiratory variables were measured in the sitting position by two inhalotherapy technicians. The FEV 1 and NIF were measured three times and the best values were recorded.

\section{Holter monitoring}

All patients in the PCA group and, because of unavailability of Holter monitors, 23 patients in the CAT group were monitored postoperatively for myocardial ischaemia with two bipolar leads applied to provide lead II and modified $\mathrm{V}_{5}$ using a solid-state ECG recorder (Cardio Data Holter PR3-ST two leads). Data recorded on cassette were subsequently read by a laser analysis system (Marquette, Laser SPX, software level 5.8). The ST segment was then trended continuously in the two leads for the duration of the tape. The baseline ST segment level was defined as the average ST segment over a stable period (at least $15 \mathrm{~min}$ ) preceding each episode of myocardial ischaemia. All abnormal QRS complexes, such as ventricular ectopic beats and beats with conduction abnormalities were excluded. Electrocardiographic changes consistent with ischaemia were defined as reversible ST depression from baseline $\geq 1 \mathrm{~mm}$ at the J-point plus $60 \mathrm{msec}$ or ST elevation $\geq 2 \mathrm{~mm}$, lasting for at least one minute. For each episode of myocardial ischaemia, the following were measured: the maximum ST segment change from baseline, duration, heart rate at the onset of myocardial ischaemia, and the area under the curve (AUC), a measure which reflects both the duration and the severity of the myocardial ischaemic episode.

\section{Haemodynamic data and clinical course}

Routine cardiac haemodynamic variables (central venous pressure, pulmonary capillary wedge pressure, cardiac index, and systemic vascular resistance) were measured for all patients. Adverse cardiac outcomes were defined as cardiac death, nonfatal myocardial infarction, and ventricular failure. A cardiac death was recorded if the patient died from myocardial infarction, dysrhythmia, or heart failure. Myocardial infarction was diagnosed in the presence of an elevation of creatine kinase $\mathrm{MB}$ isoenzyme $\left(\geq 50 \mathrm{U} \cdot \mathrm{L}^{-1}\right.$ ) and the development of a new $\mathrm{Q}$ wave. A diagnosis of ventricular failure required a cardiac index $<2 \mathrm{~L} \cdot \mathrm{min}^{-1} \cdot \mathrm{m}^{-2}$. The following variables were recorded prospectively: time to awaken, time to extubation, and times to discharge from ICU and from hospital. In addition, the following clinical side effects were evaluated: nausea, vomiting, constipation, urinary retention and pruritus.

\section{Statistical analysis}

All values are expressed as means \pm standard deviation. Groups were compared using factorial analysis of variance. Values obtained at each time were compared using analysis of variance for repeated measures. Chi-square analyses were used to compare noncontinuous demographic data, pain score and incidence of myocardial ischaemia and side effects.

\section{Results}

Seventy-two patients were enrolled in the study and 12 
TABLE I Reasons for exclusion from the study

\begin{tabular}{lll}
\hline & $P C A$ & $C A T$ \\
\hline Late extubation & 3 & 3 \\
Patient confused/agitated & 1 & 2 \\
Death (intraoperative) & 1 & 0 \\
Postoperative sedation not respected & 0 & 1 \\
PCA pump failure & 1 & - \\
\hline
\end{tabular}

CAT $=$ Conventional analgesic therapy; PCA $=$ Patient-controlled analgesia.

TABLE II Preoperative demographic and clinical data

\begin{tabular}{lcc}
\hline & PCA group & CAT group \\
\hline Age (yr) & $59.5 \pm 6.4$ & $60.5 \pm 7.5$ \\
Height (cm) & $168 \pm 6$ & $167 \pm 9$ \\
Weight (kg) & $81.5 \pm 13.2$ & $76 \pm 14.7$ \\
Sex (F:M) & $3: 27$ & $7: 23$ \\
Ejection fraction (\%) & $53.7 \pm 14.3$ & $52.7 \pm 15.4$ \\
Preoperative medication & & \\
Beta blockers & 19 & 18 \\
Calcium blockers & 23 & 12 \\
Nitrates & 19 & 19 \\
\hline
\end{tabular}

$\mathrm{CAT}=$ Conventional analgesic therapy; $\mathrm{PCA}=$ Patient-controlled analgesia.

patients were excluded, six in each group. The reasons for exclusion are listed in Table I. Demographic and clinical data for the remaining 60 patients are presented in Table II.

Haemodynamic variables, use of vasoactive drugs, awakening time, duration of intubation and adverse cardiac outcomes were similar between groups (Table III). Preoperative and postoperative pulmonary lung functions are shown in Table IV. There was no difference in preoperative lung function between groups. Both groups demonstrated a marked deterioration after tracheal extubation when compared with control values $(P<0.001)$. This deterioration persisted over the next three days and was similar in both groups.

Two Holter tracings from the PCA group were uninterpretable for Holter analysis and excluded. Analysis of the remaining Holter recording (28 PCA patients and 23 CAT patients) revealed a lower number of ischaemic events in the PCA group on the third postoperative day (Table V), but the maximum ST deviation, heart rate, duration and AUC were not different between groups (Figure 1). Approximately 50\% of myocardial ischaemic episodes were associated with tachycardia (heart rate $\geq$ $100 \mathrm{bpm}$ ). One perioperative myocardial infarction occurred in each group. The length of ICU and hospital stay was similar in both groups (Table III).
TABLE III Perioperative haemodynamic and clinical data

\begin{tabular}{|c|c|c|}
\hline Extracorporeal circulation & PCA group & $C A T$ group \\
\hline Cross-clamp time (min) & $50.3 \pm 15.1$ & $46.1 \pm 16.1$ \\
\hline Total bypass time (min) & $80.8 \pm 25.4$ & $80 \pm 21.7$ \\
\hline \multicolumn{3}{|l|}{ Number of grafts } \\
\hline - Mammary & 25 & 29 \\
\hline - Saphenous vein & 23 & 23 \\
\hline Blood losses (ml) & $1222 \pm 520$ & $1128 \pm 509$ \\
\hline \multicolumn{3}{|l|}{ Postoperative } \\
\hline - Time to eye opening (hr) & $6.6 \pm 3.7$ & $5.4 \pm 2.8$ \\
\hline - Time to extubation $(\mathrm{hr})$ & $17.4 \pm 2.7$ & $17.7 \pm 2.4$ \\
\hline \multicolumn{3}{|l|}{ Haemodynamic } \\
\hline \multicolumn{3}{|l|}{ Post-induction } \\
\hline - Cardiac index $\left(\mathrm{L} \cdot \mathrm{min} \cdot \mathrm{m}^{-2}\right)$ & $2.3 \pm 0.56$ & $2.23 \pm 0.37$ \\
\hline - Heart rate (bpm) & $57.8 \pm 13.1$ & $55.9 \pm 8.8$ \\
\hline Systemic vascular resistance & $1259.3 \pm 349.5$ & $1315.1 \pm 362.9$ \\
\hline \multicolumn{3}{|l|}{ After bypass } \\
\hline - Cardiac index $\left(\mathrm{L} \cdot \mathrm{min} \cdot \mathrm{m}^{-2}\right)$ & $2.64 \pm 0.63$ & $2.85 \pm 0.71$ \\
\hline Heart rate (bpm) & $76.3 \pm 14.4$ & $72.0 \pm 12.7$ \\
\hline Systemic vascular resistance & $1170.8 \pm 347.4$ & $1092.1 \pm 404.6$ \\
\hline \multicolumn{3}{|l|}{ After extubation } \\
\hline - Cardiac index $\left(L \cdot \min \cdot \mathrm{m}^{-2}\right)$ & $3.73 \pm 0.76$ & $3.38 \pm 0.66$ \\
\hline - Heart rate (bpm) & $85.1 \pm 15.4$ & $83.3 \pm 10.1$ \\
\hline Systemic vascular resistance & $854 \pm 287$ & $1037 \pm 284$ \\
\hline \multicolumn{3}{|l|}{ Vasoactive drug use } \\
\hline - Nitroglycerine (hr) & $22.7 \pm 9.2$ & $19.1 \pm 7.2$ \\
\hline - Nitroprusside (hr) & $9.9 \pm 10$ & $8.9 \pm 5.9$ \\
\hline - Inotropic support (hr) & $8.1 \pm 13.9$ & $6.2 \pm 11.4$ \\
\hline \multicolumn{3}{|l|}{ Discharge from } \\
\hline - ICU (day) & $3.52 \pm 1.55$ & $3.63 \pm 2.0$ \\
\hline - Hospital (day) & $7.60 \pm 1.38$ & $7.63 \pm 3.03$ \\
\hline \multicolumn{3}{|l|}{ Adverse cardiac outcome } \\
\hline - Myocardial infarction & 1 & 1 \\
\hline Cardiac death & 0 & 0 \\
\hline Congestive heart failure & 0 & 0 \\
\hline
\end{tabular}

$\mathrm{CAT}=$ Conventional analgesic therapy; PCA $=$ Patient-controlled analgesia.

Analysis of the pain scores shown in Figure 2 revealed differences between the groups only at extubation and on the third postoperative day where the score in the PCA group was lower than the CAT group $(P<0.05)$. Day-to-day comparisons within groups showed that the PCA patients had less pain $(P<0.001)$ while the CAT average pain scores remained unchanged (Figure 2). The incidence of moderate to severe pain (defined as a pain score $>5$ ) was also analyzed and found to be less frequent by the third postoperative day in the PCA group (Figure 3). To proceed with the analysis of the narcotic requirements, the doses for hydromorphone, meperidine and codeine were converted to morphine equivalency. There were no differences in analgesic requirement between the CAT and PCA groups (Table VI). Very few PCA infusions needed adjustments (two infusions stopped and three infusions increased) while ten CAT patients required supplemental im meperidine for inadequate pain relief. There were no differences between the two modes of ther- 
TABLE IV Preoperative and postoperative pulmonary lung functions

\begin{tabular}{|c|c|c|c|c|c|c|}
\hline \multirow[b]{2}{*}{ Lung function } & \multicolumn{2}{|l|}{ Preoperative } & \multicolumn{2}{|l|}{ Extubation } & & \\
\hline & $P C A$ & $C A T$ & $P C A$ & $C A T$ & & \\
\hline Forced vital capacity (L) & $3.47 \pm 0.74$ & $3.53 \pm 1.02$ & $1.13 \pm 0.4^{*}$ & $1.12 \pm 0.4 \dagger$ & & \\
\hline Forced expiratory volume $1 \sec (\mathrm{L})$ & $2.83 \pm 0.66$ & $2.76 \pm 0.91$ & $0.98 \pm 0.3^{*}$ & $0.97 \pm 0.3 \dagger$ & & \\
\hline Negative inspiratory force $\left(\mathrm{cm} \mathrm{H}_{2} \mathrm{O}\right)$ & $58.6 \pm 25$ & $70.6 \pm 33$ & $34.8 \pm 20^{*}$ & $29.8 \pm 25 \dagger$ & & \\
\hline Tidal volume $(\mathrm{L})$ & $0.93 \pm 0.46$ & $0.82 \pm 0.41$ & $0.61 \pm 0.2^{*}$ & $0.54 \pm 0.13 \dagger$ & & \\
\hline $\mathrm{pH}$ & $\mathrm{N} / \mathrm{A}$ & N/A & $7.39 \pm 0.03$ & $7.37 \pm 0.03$ & & \\
\hline $\mathrm{PaO}_{2}$ & N/A & $\mathrm{N} / \mathrm{A}$ & $130.6 \pm 41.2$ & $140.2 \pm 45.4$ & & \\
\hline \multirow[t]{2}{*}{$\mathrm{PaCO}_{2}$} & $\mathrm{~N} / \mathrm{A}$ & $\mathrm{N} / \mathrm{A}$ & $44.4 \pm 4.1$ & $43.0 \pm 3.8$ & & \\
\hline & \multicolumn{2}{|l|}{ Postop day 2} & \multicolumn{2}{|l|}{ Postop day 3} & \multicolumn{2}{|l|}{ Postop day 4} \\
\hline Lung function & $\overrightarrow{P C A}$ & $C A T$ & $P C A$ & $C A T$ & $P C A$ & $C A T$ \\
\hline Forced vital capacity (L) & $1.03 \pm 0.3^{*}$ & $1.04 \pm 0.4 \dagger$ & $1.28 \pm 0.4^{*}$ & $1.27 \pm 0.4 \dagger$ & $1.65 \pm 0.5^{*}$ & $1.55 \pm 0.5 \dagger$ \\
\hline Forced expiratory volume $1 \mathrm{sec}(\mathrm{L})$ & $1.00 \pm 0.4^{*}$ & $0.92 \pm 0.3 \dagger$ & $1.05 \pm 0.3^{*}$ & $1.04 \pm 0.4 \dagger$ & $1.35 \pm 0.4^{*}$ & $1.24 \pm 0.4 \dagger$ \\
\hline Negative inspiratory force $\left(\mathrm{cm} \mathrm{H}_{2} \mathrm{O}\right)$ & $34 \pm 24^{*}$ & $37.8 \pm 37 \dagger$ & $45.9 \pm 33^{*}$ & $37.8 \pm 22 \dagger$ & $50.4 \pm 33^{*}$ & $45.8 \pm 34 \dagger$ \\
\hline Tidal volume $(\mathrm{L})$ & $0.57 \pm 0.14^{*}$ & $0.56 \pm 0.16 \dagger$ & $0.65 \pm 0.2^{*}$ & $0.59 \pm 0.2 \uparrow$ & $0.71 \pm 0.3$ & $0.71 \pm 0.2$ \\
\hline $\mathrm{pH}$ & $7.39 \pm 0.03$ & $7.38 \pm 0.03$ & $7.40 \pm 0.03$ & $7.40 \pm 0.03$ & $\mathrm{~N} / \mathrm{A}$ & N/A \\
\hline $\mathrm{PaO}_{2}$ & $110 \pm 30.1$ & $111.1 \pm 24.9$ & $99.4 \pm 32.9$ & $100 \pm 31.8$ & N/A & N/A \\
\hline $\mathrm{PaCO}_{2}$ & $44.6 \pm 4.7$ & $44.7 \pm 3.9$ & $42.9 \pm 5.3$ & $43.5 \pm 4.6$ & N/A & N/A \\
\hline
\end{tabular}

CAT $=$ Conventional analgesic treatment; $\mathrm{PCA}=$ Patient-controlled analgesia.

*Different from preoperative PCA value $P<0.001$.

†Different from preoperative CAT value $P<0.001$.

TABLE V Number of patients, episodes, duration of ischaemia and range of heart rate as detected by Holter monitoring

\begin{tabular}{|c|c|c|c|c|c|c|c|c|}
\hline \multirow[b]{2}{*}{ Period } & \multicolumn{4}{|c|}{ CAT group (23 Holter Analyses) } & \multicolumn{4}{|c|}{ PCA group (28 Holter analyses) } \\
\hline & $\begin{array}{l}\text { Nb of } \\
\text { patients with } \\
\text { ischaemia }\end{array}$ & $\begin{array}{l}\text { Nb of } \\
\text { ischaemic } \\
\text { episodes }\end{array}$ & $\begin{array}{l}\text { Duration } \\
\text { min (range) }\end{array}$ & $\begin{array}{l}\text { Mean heart } \\
\text { rate (range) }\end{array}$ & $\begin{array}{l}\text { Nb of } \\
\text { patients with } \\
\text { ischaemia }\end{array}$ & $\begin{array}{l}\text { Nb of } \\
\text { ischaemic } \\
\text { episodes }\end{array}$ & $\begin{array}{l}\text { Duration } \\
\text { min (range) }\end{array}$ & $\begin{array}{l}\text { Mean heart } \\
\text { rate (range) }\end{array}$ \\
\hline Extubation & 2 & 2 & $14-30$ & $(58-91)$ & 2 & 2 & $16-30$ & $(77-90)$ \\
\hline Day 1 & 10 & 14 & $5-300$ & $87(73-100)$ & 8 & 11 & $5-360$ & $87(56-111)$ \\
\hline Day 2 & 2 & 3 & $10-20$ & $94(91-100)$ & 3 & 3 & $3-60$ & $100(90-111)$ \\
\hline Day 3 & 7 & 13 & $5-259$ & $98(50-125)$ & 3 & $4^{*}$ & $5-30$ & $120(118-120)$ \\
\hline
\end{tabular}

CAT $=$ Conventional analgesic treatment; $\mathrm{PCA}=$ Patient-controlled analgesia.

*Different from CAT with $P<0.01$.

apy in the degree of sedation and the incidence of various side effects such as nausea, pruritus, etc.

\section{Discussion}

Patient-controlled analgesia is a modality not only designed to meet the highly variable analgesic requirements that we traditionally experience when managing postoperative pain, but also avoids the pharmacokinetic variability observed with other analgesic protocols. Most clinical studies conclude that PCA technique provides better pain relief than prn or scheduled intramuscular therapy. ${ }^{12-15}$ Our findings validate the use of PCA in post- operative cardiac surgery patients, providing better pain relief than conventional analgesic therapy.

Our data show that both groups experience mild to moderate pain at rest. The PCA pain scores as measured by VAS were lower at extubation (acute pain response) and on the third postoperative day. Furthermore, the incidence of moderate to severe pain was zero for PCA patients on the third postoperative day. These results are in agreement with those of Coyle et al. ${ }^{16}$ for CABG patients. However, we failed to see a difference in pain relief between the two groups on days one and two postoperatively. Irrespective of individual analgesic requirements, 

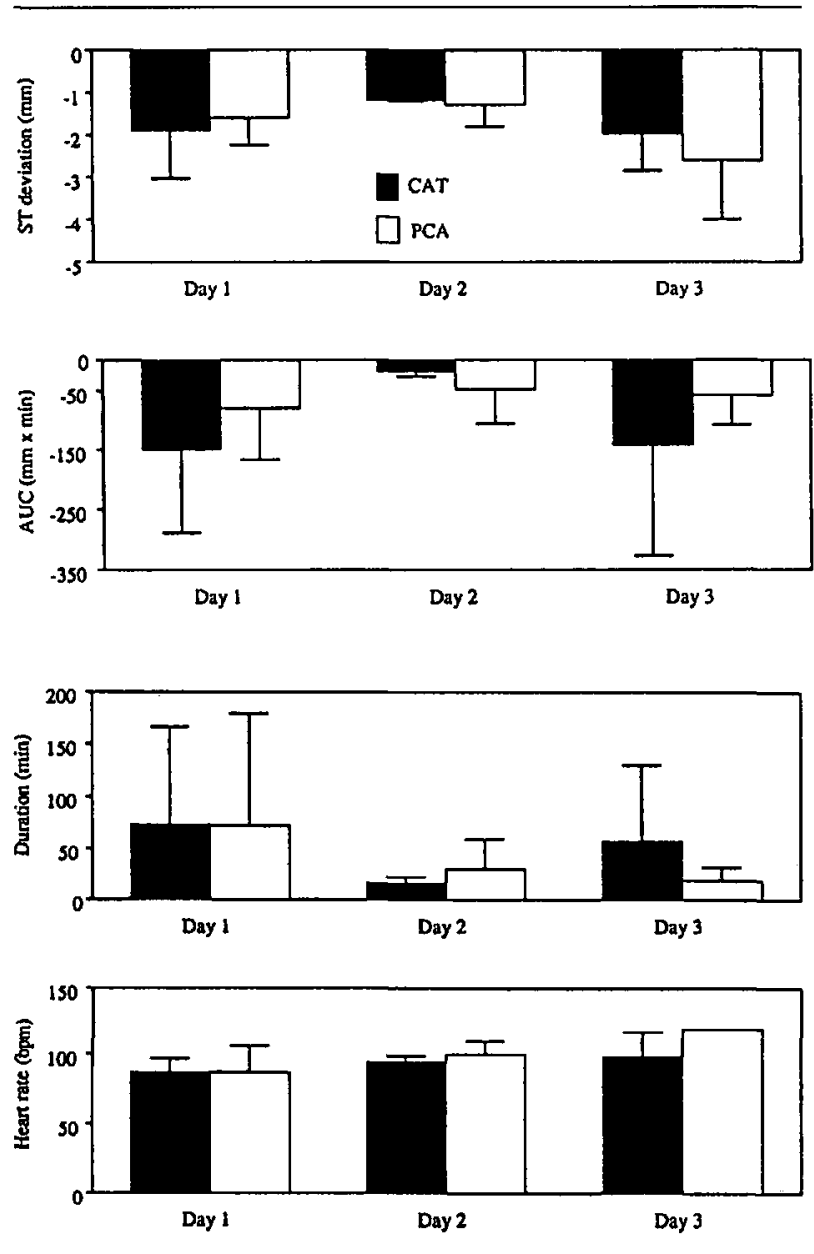

FIGURE 1 Characteristics of ECG ischaemic episodes between CAT and PCA. Shown are the mean ST-segment deviation, area under the ST-segment-time curve (AUC), ST-segment duration and heart rate.

the individual decision to press or not the patient-demand button, remains paramount. Fear of addiction or respiratory depression, older patients, intensive care environment, lingering effect of the anaesthetic agents, confusion or other temporary neuropsychological effects of the cardiopulmonary bypass are all significant factors which may have influenced patients to accept higher levels of pain and be unable to gain maximum benefit from PCA..$^{6,17-19}$ Furthermore, the lack of exposure and unfamiliarity with PCA modality may have caused a certain apprehension at the beginning and required an adaptation period and a learning process.

There were no differences between the two groups in the total opioid requirements, pulmonary function tests, sedation and side effects and these findings are in agreement with more recent studies. ${ }^{20-22}$ The group of patients using PCA had improvement in pain relief during the study period while the group receiving the conventional

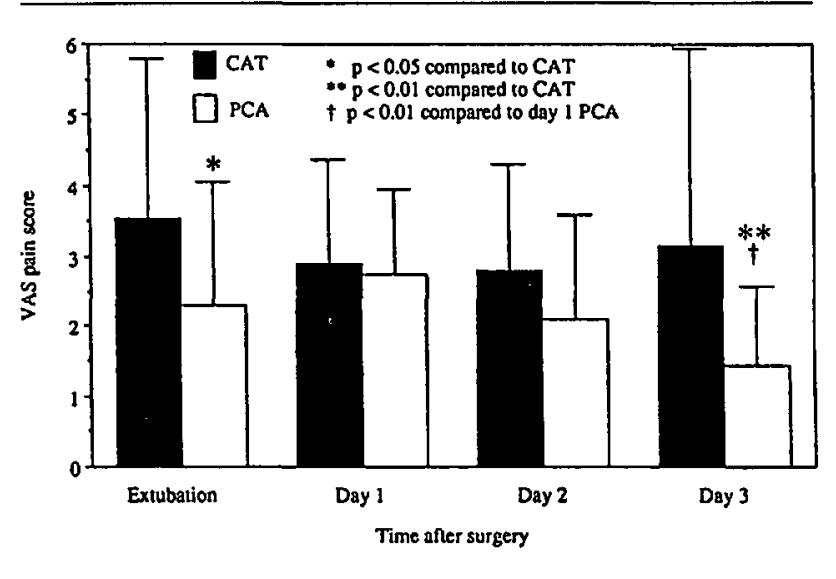

FIGURE 2 Pain scores as measured by VAS at extubation (acute pain score) and at different times after surgery. Values are the average $\pm \mathrm{SD}$.

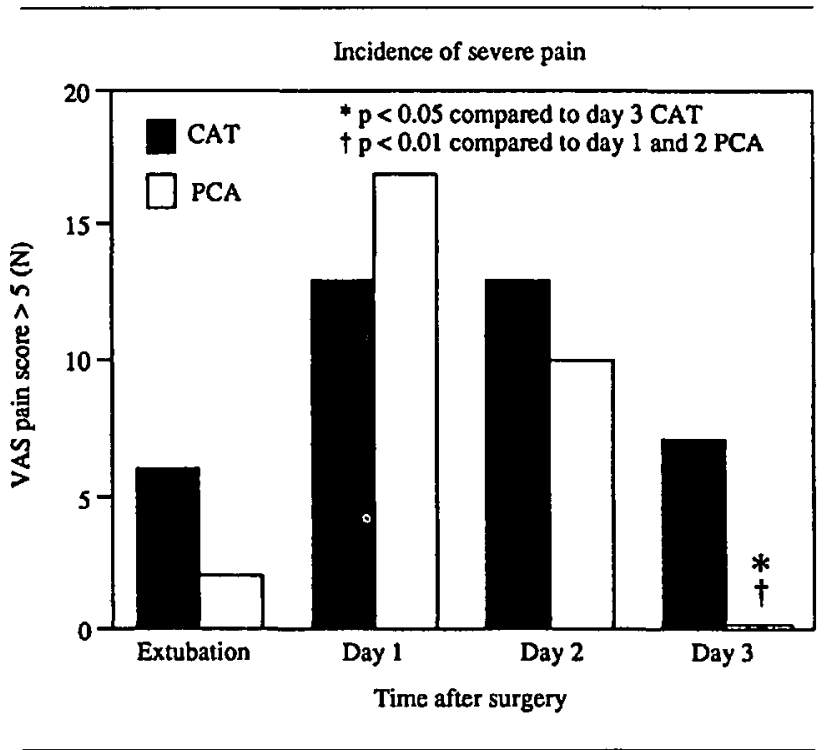

FIGURE 3 Number of patients reporting at least one VAS pain score $>5$ at different times after surgery.

analgesic therapy continued to experience the same degree of pain during the same period. As already mentioned, we believe that the lower quality of pain relief obtained in the CAT group is not attributable to the lack of effective analgesic agents but rather to the inappropriate manner in which these agents are delivered. ${ }^{3,4}$

The incidence of ischaemic episodes seen in this study was similar to those previously reported. ${ }^{23-25}$ Although there was a lower incidence in the number of myocardial ischaemic episodes in the PCA patients (Table V) on the thind postoperative day, no difference in maximum ST ischaemic changes, duration, heart rate, and severity (AUC) were observed. Mangano et al. ${ }^{23}$ have shown that 
TABLE VI The average \pm SD analgesic requirement for the two groups and expressed as per total number of mg of morphine equivalency. The range of values is indicated in parentheses.

\begin{tabular}{|c|c|c|c|c|c|}
\hline Group & Hydromorphone (mg) & Morphine ( $m g$ ) & Meperidine (mg) & Codeine ( $m g$ ) & Morphine equivalency (mg)* \\
\hline PCAt & $\begin{array}{l}13.4 \pm 6.2 \\
(2.5-25)\end{array}$ & $\mathbf{N} / \mathbf{A}$ & N/A & N/A & $63.7 \pm 13.5$ \\
\hline $\mathrm{CAT}_{\ddagger}^{+}$ & N/A & $\begin{array}{l}13.6 \pm 4.9 \\
(5-24.5)\end{array}$ & $\begin{array}{l}266.3 \pm 136.9 \\
(0-500)\end{array}$ & $\begin{array}{l}215 \pm 101.2 \\
(0-420)\end{array}$ & $58.1 \pm 14.7$ \\
\hline
\end{tabular}

* $1 \mathrm{mg}$ of morphine $=0.2 \mathrm{mg}$ hydromorphone, $10 \mathrm{mg}$ of meperidine and $12 \mathrm{mg}$ of codeine.

†Five PCA patients had their infusion adjusted, two stopped and three increased.

$\ddagger$ Ten CAT patients required supplemental im meperidine during oral medication. CAT $=$ Conventional analgesic treatment; N/A = Not applicable;

PCA $=$ Patient-controlled analgesia.

intense analgesia during the ICU period effectively reduces the incidence and severity of myocardial ischaemia. The lower average pain score and the absence of patient reporting severe pain on the third day may have been associated with the lower incidence of myocardial ischaemia. This is only conjecture since the mechanism for the reduced incidence of myocardial ischaemia in our study remains uncertain, and the size of our study population cannot answer this question. Further therapeutic trials are necessary to determine the relative efficacy of different techniques and agents as well as the optimal dosing and duration of administration of analgesics.

\section{Study limitations}

Inherent to the study design, we had to use different drugs between the two groups. Thus, we aimed at equipotent analgesic techniques for both groups. The combination of meperidine im and acetaminophen with codeine po that we defined as conventional analgesic therapy is still widely used for pain relief in postoperative cardiac surgery patients. Our primary objective was to assess the effectiveness and feasibility of PCA technique compared with this conventional therapy. Our findings may have limitations in its applicability to other cardiac centres not using the same conventional therapy.

We assume that ST-segment abnormalities observed on Holter monitoring truly indicate myocardial ischaemia. However, nonspecific ST-segment abnormalities may occur due to changes in body temperature or serum electrolytes, and may be seen following cardiac surgery or drug therapy such as digoxin. Nevertheless, there is no established standard reference to detect spontaneous occurrence of myocardial ischaemia and Holter analysis remains the most practical over a prolonged postoperative period.

Although we found a lower incidence of postoperative myocardial ischaemia in the group of patients using PCA, conclusive evidence linking adverse outcome to the presence of postoperative myocardial ischaemia in CABG patients is controversial. In addition, we do not understand the importance of postoperative myocardial ischaemia following cardiac surgery and late outcomes (i.e., recurrence of angina, myocardial infarction, death, etc.) when compared to patients with no postoperative ischaemic event.

\section{Conclusions}

The results of this study show that the PCA technique using hydromorphone achieves a slightly better postoperative pain relief, is safe and has minimal side effects and sedation in patients undergoing cardiac surgery when compared with the conventional analgesic therapy. There was no difference in opioid requirements on postoperative pulmonary function. We found a lower incidence of myocardial ischaemic episodes on the third postoperative day which was associated with a lower VAS pain score, but we must await further clinical trials to confirm this finding.

\section{Acknowledgement}

The authors wish to acknowledge the excellent secretarial work of Mrs. Mary Morello and Mrs. Christine Lussier. The authors are also grateful to Drs. R. Martineau and P. Sahab for their critical review and suggestions, and Mr. Eric Lavallée for processing the Holter tapes.

\section{References}

1 Weis OF, Sriwatanakul K, Alloza JL, Weintraub M, Lasagna $L$. Attitudes of patients, housestaff, and nurses toward postoperative analgesic care. Anesth Analg 1983; 62: 70-4.

2 Marks RM, Sachar EJ. Undertreatment of medical inpatients with narcotic analgesics. Ann Intern Med 1973; 78: 173-81.

3 Eisenach JC, Grice SC, Dewan DM. Patient-controlled analgesia following cesarean section: a comparison with epidural and intramuscular narcotics. Anesthesiology 1988; 68: 444-8. 
4 Harrison DM, Sinatra $R$, Morgese L, Chung JH. Epidural narcotic and patient-controlled analgesia for postcesarean section pain relief. Anesthesiology 1988; 68: 454-7.

5 Juhl U, Christensen BV, Bülow HH, Wilbek H, Dreijer $N C$, Egelund B. Postoperative pain relief, from the patients' and the nurses' point of view. Acta Anaesthesiol Scand 1993; 37: 404-9.

6 Donovan $B D$. Patient attitudes to postoperative pain relief. Anaesth Intensive Care 1983; 11: 125-9.

7 Myers $J R$, Lembeck L, O'Kane H, Baue AE. Changes in functional residual capacity of the lung after operation. Arch Surg 1975; 110: 576-83.

8 Craig $D B$. Postoperative recovery of pulmonary function. Anesth Analg 1981; 60: 46-52.

9 Gelfand RA, Matthews DE, Bier DM, Sherwin RS. Role of counterregulatory hormones in the catabolic response to stress. J Clin Invest 1984; 74: 2238-48.

10 Tuman KJ, McCarthy RJ, March RJ, DeLaria GA, Patel $R V$, Ivankovich $A D$. Effects of epidural anesthesia and analgesia on coagulation and outcome after major vascular surgery. Anesth Analg 1991; 73: 696-704.

11 Wolman RL. Patient-controlled analgesia following thoracic surgery. In: Gravlee GP, Rauck RL (Eds.). Pain Management in Cardiothoracic Surgery, Philadelphia: J.B. Lippincott Company, 1993; 57-99.

12 Scherpereel Ph. Analgésie contrôlée par le patient (ACP). Ann Fr Anesth Réanim 1991; 10: 269-83.

13 Owen H, Mather LE, Rowley K. The development and clinical use of patient-controlled analgesia. Anaesth Intensive Care 1988; 16: 437-47.

14 Mather LE, Owen $H$. The scientific basis of patientcontrolled analgesia. Anaesth Intensive Care 1988; 16: 427-36.

15 Brown $D L$, Carpenter $R L$. Perioperative analgesia: a review of risk and benefits. J Cardiothorac Anesth 1990; 4: 368-83.

16 Coyle JP, Steele J, Cutrone F, Higgins TL, Taylor PC. Patient controlled analgesia after cardiac surgery. Anesth Analg 1990; 70: S71.

17 Ferrante FM, Orav EJ, Rocco AG, Gallo J. A statistical model for pain in patient-controlled analgesia and conventional intramuscular opioid regimens. Anesth Analg 1988; 67: 457-61.

18 Beattie WS, Buckley DN, Forrest JB. Epidural morphine reduces the risk of postoperative myocardial ischaemia in patients with cardiac risk factors. Can J Anaesth 1993; 40: 532-41.

19 Newman S. Neuropsychological and psychological changes. In: Smith PL and Taylor KM (Eds.). Cardiac Surgery and the Brain. London: Edward Arnold, 1993; 34-54.

20 Bollish SJ, Collins CL, Kirking DM, Bartlett RH.
Efficacy of patient-controlled versus conventional analgesia for postoperative pain. Clin Pharm 1985; 4: 48-52.

21 Wasylak TJ, Abbott FV, English MJM, Jeans $M-E$. Reduction of postoperative morbidity following patientcontrolled morphine. Can J Anaesth 1990; 37: 726-31.

22 Dahl JB, Daugaard JJ, Larsen HV, Mouridsen P, Nielsen TH, Kristoffersen E. Patient-controlled analgesia: a controlled trial. Acta Anaesthesiol Scand 1987; 31: 744-7.

23 Mangano DT, Siliciano D, Hollenberg $M$, et al. Postoperative myocardial ischemia. Therapeutic trials using intensive analgesia following surgery. Anesthesiology 1992; 76: 342-53.

24 Smith RC, Leung JM, Mangano DT. Postoperative myocardial ischemia in patients undergoing coronary artery bypass graft surgery. Anesthesiology 1991; 74: 464-73.

25 Knight AA, Hollenberg $M$, London $M J$, et al. Perioperative myocardial ischemia: importance of the preoperative ischemic pattern. Anesthesiology 1988; 68: 681-8. 